\title{
Gas Turbine Tubular Combustor Main Injector Optimization for Low Emission Combustion
}

\author{
Arkan Khikhal Husain \\ Mechanical Engineering Department University of Technology, Baghdad, Iraq \\ arkanltaie@yahoo.com \\ Mahmood Attallah Mashkoor \\ Mechanical Engineering Department University of Technology, Baghdad, Iraq \\ MahmoodMashkoor@hotmail.com \\ Fuad Abdul Ameer Khalaf \\ Mechanical Engineering Department University of Technology, Baghdad, Iraq \\ me.21325@uotechnology.edu.iq
}

\begin{tabular}{|l|l|l|}
\hline Submission date:- 2/4/2018 & Acceptance date:- 3/5/2018 & Publication date:- 14/11/2018 \\
\hline
\end{tabular}

\begin{abstract}
This work presents the experimental investigation results of high performance and low emission colorless combustion in a gas turbine tubular combustor at atmospheric conditions. Low emission and colorless oxidation reaction is characterized by dispersed flame and temperature under the conditions of preheated air. System performance, emissions of CO and UHC are recorded up to achieve low emission colorless combustion, the flame capturing, Measurements of temperature, inlet air mass flow rate and gas fuel LPG flow rate for variable of fuel main injector holes diameter. concluded that maximal air mass flow rate, with choked fuel flow in the main injector for each cases promotes the formation of colorless pal blue flame combustion, for $3.2 \mathrm{~g} / \mathrm{s}$ of fuel flow rate with 6 holes and $1 \mathrm{~mm}$ main injector holes diameter and lower $\mathrm{CO}$ emissions and decreasing in UHC emissions $(70 \rightarrow 10)$ ppmv with increasing in power generation $(0.5$ $\rightarrow 3.42) \mathrm{kW}$ and decreasing in S.F.C. $(21.5 \rightarrow 3.49) \mathrm{kg} / \mathrm{kwh}$.
\end{abstract}

Key words: Gas Turbine, Tubular Combustor, Colorless combustion, Low Emission, LPG Fuel.

\section{Nomenclature}

$\begin{array}{ll}\text { A } & \text { Area }[\mathrm{m} 2] . \\ \mathrm{D} & \text { Diameter }[\mathrm{m}] . \\ \mathrm{F}_{1} & \text { fuel mass flow rate in main injection line. } \\ \mathrm{L} & \text { Length }[\mathrm{m}] . \\ \mathrm{m} & \text { Flow Rate }[\mathrm{kg} / \mathrm{s}] . \\ P & \text { Total Pressure }[\mathrm{Pa}] . \\ P_{r} & \text { Pressure Ratio }(P 3 / P 1) . \\ \text { qRef } & \text { Dynamic pressure along the combustor. } \\ \text { S. F. C } & \text { Specific fuel consumption. } \\ \text { S. L. F. I } & \text { Secondary line of fuel injection. } \\ \text { T } & \text { Total Temperature }[\mathrm{K}] . \\ \text { V } & \text { Velocity }[\mathrm{m} / \mathrm{s}] .\end{array}$

Journal of University of Babylon for Engineering Sciences by University of Babylon is licensed under a Creative Commons Attribution 4.0 International License. 
Journal of University of Babylon for Engineering Sciences, Vol. (26), No. (10): 2018.

\section{Greek Symbols}

$\theta \quad$ Angle (Diffuser or Snout or Dome) $\left[{ }^{\circ}\right]$.

Bsw $\quad$ Swirler Blade Stagger Angle (Flat Blade) $\left[{ }^{\circ}\right]$.

$\begin{array}{ll}\text { Subscripts } & \\ 1 & \text { At Compressor Inlet. } \\ 3 & \text { At Combustor Inlet. } \\ 4 & \text { At Combustor Outlet. } \\ \text { f } & \text { Fuel. } \\ \text { Ref } & \text { Reference section. } \\ \text { RZ } & \text { Recirculation Zone. } \\ \text { PZ } & \text { Primary Zone. } \\ \text { SZ } & \text { Secondary Zone. } \\ \text { DZ } & \text { Dilution Zone. } \\ \text { diff } & \text { Diffuser. } \\ \text { Lin } & \text { Liner. } \\ \text { sw } & \text { Swirler. } \\ \text { h } & \text { Hole. }\end{array}$

\section{Introduction:}

The oxidation reaction in a gas turbine combustor is to add the thermal energy to the system to power the turbine, Combustor must be designed to produce stable combustion for injected fuel and optimum generated heat within the limited combustor size available and over a maximal range of air/fuel ratios. The combustor is fed by high pressure air by the compressor therefor the combustor must preserve stable combustion despite high air flow rates. Combustion chambers are designed to mix and ignite the air and fuel mixture, and then mix in more added air to complete the combustion, [1]. This work present the experimental results for a variable holes diameter of the main injector of the combustor capable of achieving colorless low emission combustion. Colorless low emission oxidation reaction is characterized by reacting fuel with a high oxidizer temperature with high levels of turbulence producing a highly dispersed reaction zone. The highly dispersed reaction zone eliminates hot spots, the turbulence levels of the colorless oxidation reaction is so high that if operated in the current diffusion flame combustion technology, [2]. Swirl flows has been adopted to obtain internal recirculation rates in colorless combustion mode. The preference of LPG is chosen from this work for micro gas turbines have a wider scope of fuel. [3], examined experimentally flameless oxidation to reduce thermal NO-formation they concluded that there are two approaches are concerned with the reduction of NOx emission. In this regard, the first approach deals with NOx abatement strategies regarding control of NOx formation via thermal mechanisms which avoid hot spot zones within the chamber. Another attempts to eliminate NOx after formation indicates the methods used in NOx abatement strategies. However most NOx technique are aimed at lowering the peak temperature and maintaining the residence time along with lower concentration of oxygen via dilution in high temperature zone (wunning and wunning 1997) these strategies can be classified in to three main categories : injection of diluent, exhaust gases clean-up and NOx formation prevention. These methods are crucial in the reduction of NOx formation by reducing the combustion chamber temperature (thermal NOx prevention), improve mixing or exhaust gases clean-up in which Nox is reduced after formation. [4]studied numerically the effect of syngas fuel mixture on the combustion of tubular combustor of gas turbine in gas turbine to shows the effects of the variability in fuel composition type and heating value on emission gases and combustion quality. The chemical composition of the used fuel was changed from methane to syngas fuel with hydrogen to carbon monoxide (H2/CO) volume ratio ranging from 0.63 to 2.36 . Concluded changes in gas turbine quality with the same power generation when methane fuel is replace by syngas fuels. The gas temperature for the all type of used syngas reveal a lower gas temperature compared to the temperature of methane fuel, the gas temperature reduction depends on lower heating value and the combustible and non-combustible As a result some knowledge about utilization of Methane is carried out. [5], studied numerically the effects of the swirler bled angle on the temperature profile at the outlet section of the combustor and the NO emissions in can- combustor. By using both PDF flamelet and LED models for methane fuel combustion models and $\mathrm{k}-\varepsilon$ as turbulent model, concluded that the $60^{\circ}$ swirler bled angle geometry is giving less NO emission as the temperature at the exit 
of combustion chamber is less as compared to $30^{\circ}$ and $45^{\circ}$ swirler angle geometry. So that for further numerical analysis $60^{\circ}$ geometry is used. [6], studied numerically the of the turbulent intensity on the combustion in gas turbine tubular combustion chamber. For methane fuel with SST turbulent model and LED combustion model results showed that the turbulent intensity is high in the immediate vicinity of the ramp injector indicating a superior air-fuel mixing. A very high turbulent intensity indicates a superior air-fuel mixing. The high value of mass fraction of NO formed indicates an efficient combustion process. [7], studied numerically the effects of the Position of injected air holes in Primary and Secondary Zones on the exit temperature profile (pattern factor) on can combustor of Gas Turbine for Ethanol fuel, using the FLUENT package with SST adopted model for turbulent flow and Non-Premixed Combustion PDF flamlet model foe combustion processes, Were varied air injection holes positions of the primary and secondary zone and fixed the location of the dilution zone holes. For this purpose each zone primary and secondary lengths are divided into four sub length: $25 \%, 50 \%, 75 \%$ and $100 \%$ of their original length dimensions. Concluded that the positioning of the Primary zone holes has a great influence on the pattern factor than the positioning of Secondary zone holes, pattern factor shows high sensitive to rows of primary holes displacements. For the Primary zone holes, a reasonable explanation is based on the fact that there is a strong revers flow zone in the first three quarters of the Primary zone length. This condition is observed when positioning the Primary zone holes row in downstream these $3 / 4$ of the primary zone length, in other words, thereby reducing the demand on the downstream zones in obtaining lower pattern factor.

Design methodologies would be useful for researchers for preliminary design assessments of a gas turbine combustor. In this study, step by step design methodologies of tubular combustor have been carried. The effect of the main port fuel injection has also been studied experimentally where that the hole size of the main fuel injector has important role in the performance of combustor.

The overall contribution to knowledge of this study is development of combustor fuel injection methodologies with different variants. The other contribution to knowledge is related to novel combustors with a capability to produce low emissions.

\section{Combustor Preliminary design calculation:}

For the preliminary design of the combustor, a computational tool for Gas Turbine Combustor Design (GTCD) was used and implemented in mathcad15, developed by J. Saywers [2], H. Lefebvre [9]. With this tool, it is possible to get the preliminary design of tubular combustor. The GTCD enables the design of combustors fueled by LPG fuel, provided that changed the thermochemical parameters of temperature increase as a function of equivalence ratio for fuel adopted. Such a design methodology, in which GTCD is based, considers for the design of combustors, two criteria that must be met in all conditions of the operating envelope of the combustor: aerodynamic and thermochemical. Obtained for both criteria the reference area of the casing cross section $\left(A_{r e f}\right)$, corresponding to the combustor in study. It is adopted in designing the reference area that meets both criteria above. Defined $A_{\text {ref }}$, obtained the following calculations performed by the tool, the main ones being:

- Diameter of the liner $\left(D_{\text {Lin }}\right)$.

- Longitudinal lengths of the primary zone $\left(L_{P z}\right.$, secondary zone $\left(L_{S z}\right)$ and dilution zone $\left(L_{D z}\right)$.

- Dimensions of the diffuser $\left(L_{D i f f}\right)$ and swirler diameter $\left(D_{S w}\right)$.

- Diameter of primary zone holes $\left(D_{P h}\right)$, secondary zone hols $\left(D_{S h}\right)$ and dilution zone holes $\left(D_{D h}\right)$.

For the aerodynamic criterion if the combustor is dimensioned for a certain pressure loss, it will be large enough to accommodate the chemical reaction, J. Saywers [2]. The mixing process of fuel and air is extremely important. A good mix in the primary zone is essential for high burning rate and to minimize UHC and soot formation, H. Lefever [9] and S. Cohen [1]. A satisfactory mixture air-fuel inside the flame tube, and a relatively steady flow throughout the chamber, are aimed in the design of combustor, leading consequently to shorter combustors and lower pressure losses.

By the aerodynamic criterion, preliminary casing and flame tube diameters are estimated using equations (1) and (2). 


$$
\begin{aligned}
& A_{\text {ref }}=\left[\frac{R_{\text {air }}}{2} \cdot\left[\frac{m_{3} \cdot \sqrt{T_{3}}}{p_{3}}\right]^{2} \cdot\left[\frac{\frac{\Delta p_{3-4}}{q_{\text {ref }}}}{\frac{\Delta p_{3-4}}{p_{3}}}\right]\right]^{0.5} \\
& \frac{A_{\text {lin }}}{A_{\text {ref }}}=0.65
\end{aligned}
$$

The aerodynamic phenomena play a vital role in the design and performance of the gas turbine combustion. As already mentioned, generally, if the aerodynamic design is satisfactory and the fuel injection system is suitable for the combustor, so do not expect operational problems. Using Mathcad package to programming the above equations 1 and 2 for the combustor inlet boundary conditions in table 1 to get the final preliminary design results in table 2 .

Table: 1, inlet boundary condition

\begin{tabular}{|c|c|c|}
\hline Variable & Value & Unite \\
\hline $\boldsymbol{m}_{3}$ & 0.6 & $\mathrm{Kg} / \mathrm{s}$ \\
\hline $\boldsymbol{m}_{\boldsymbol{f}}$ & 0.0032 & $\mathrm{Kg} / \mathrm{s}$ \\
\hline $\boldsymbol{P}_{\mathbf{3}}$ & $1.5 E 5$ & $\mathrm{pa}$ \\
\hline $\boldsymbol{P r}$ & 1.4 & - \\
\hline $\boldsymbol{T}_{\mathbf{3}}$ & 600 & $\mathrm{~K}$ \\
\hline $\boldsymbol{V}_{\mathbf{3}}$ & 50 & $\mathrm{~m} / \mathrm{s}$ \\
\hline
\end{tabular}

Table: 2, preliminary design results.

\begin{tabular}{|c|c|c|}
\hline Variable & Value & Unite \\
\hline $\boldsymbol{A}_{\text {ref }}$ & 0.0346 & $m^{2}$ \\
\hline $\boldsymbol{A}_{\text {lin }}$ & 0.0224 & $m^{2}$ \\
\hline $\boldsymbol{A}_{\boldsymbol{s w}}$ & $8.329 e-4$ & $m^{2}$ \\
\hline $\boldsymbol{D}_{\boldsymbol{r e f}}$ & 0.21 & $m$ \\
\hline $\boldsymbol{D}_{\text {lin }}$ & 0.17 & $m$ \\
\hline $\boldsymbol{D}_{\boldsymbol{s w}}$ & 0.048 & $m$ \\
\hline $\boldsymbol{D}_{\boldsymbol{s} \text {,hub }}$ & 0.025 & $m$ \\
\hline $\boldsymbol{L}_{\boldsymbol{p} z}$ & 0.1269 & $m$ \\
\hline $\boldsymbol{L}_{\boldsymbol{s z}}$ & 0.0846 & $m$ \\
\hline $\boldsymbol{L}_{\boldsymbol{d z}}$ & 0.225 & $m$ \\
\hline $\boldsymbol{L}_{\boldsymbol{D i f f}}$ & 0.038 & $m$ \\
\hline $\boldsymbol{L}_{\boldsymbol{D o m}}$ & 0.0223 & $m$ \\
\hline $\boldsymbol{D}_{\boldsymbol{p h}}$ & 0.022 & $m$ \\
\hline $\boldsymbol{D}_{\boldsymbol{s h}}$ & 0.014 & $m$ \\
\hline $\boldsymbol{D}_{\boldsymbol{D h}}$ & 0.032 & $m$ \\
\hline $\boldsymbol{\theta}_{\text {Dom }}$ & 69.86 & $\boldsymbol{o}$ \\
\hline $\boldsymbol{\theta}_{\text {Diff }}$ & 26.3 & $\boldsymbol{o}$ \\
\hline & & \\
\hline
\end{tabular}

\section{Combustor Geometry:}

In this section, the final dimensions results of preliminary design in table 3 have drawn as geometry through employing AutoCAD 2016. The mainstream of the main injector line. However, the geometry that utilized in the experimental study as shown in Figure (1).

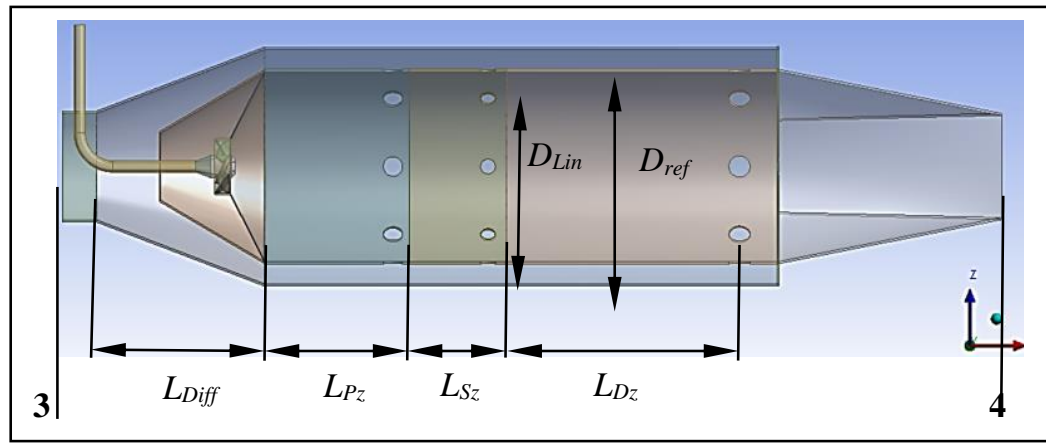

Figure: 1, final combustor geometry for the preliminary design results. 


\section{Experimantal Setup:}

The design and manufacturing of the test rig, consisting of micro gas turbine close loop system, was carried out at the Department of Mechanical Engineering, University of Technology, Exhaust gases turbocharger BBC type, exhaust plenum, exhaust gases recirculation (EGR) line, intake projection venture's tube, oil lubrication system, ignition system, bearing cooling system, pitot-tube and other measurement device, the detail of the overall test rig setup is presented in figures: 2 .

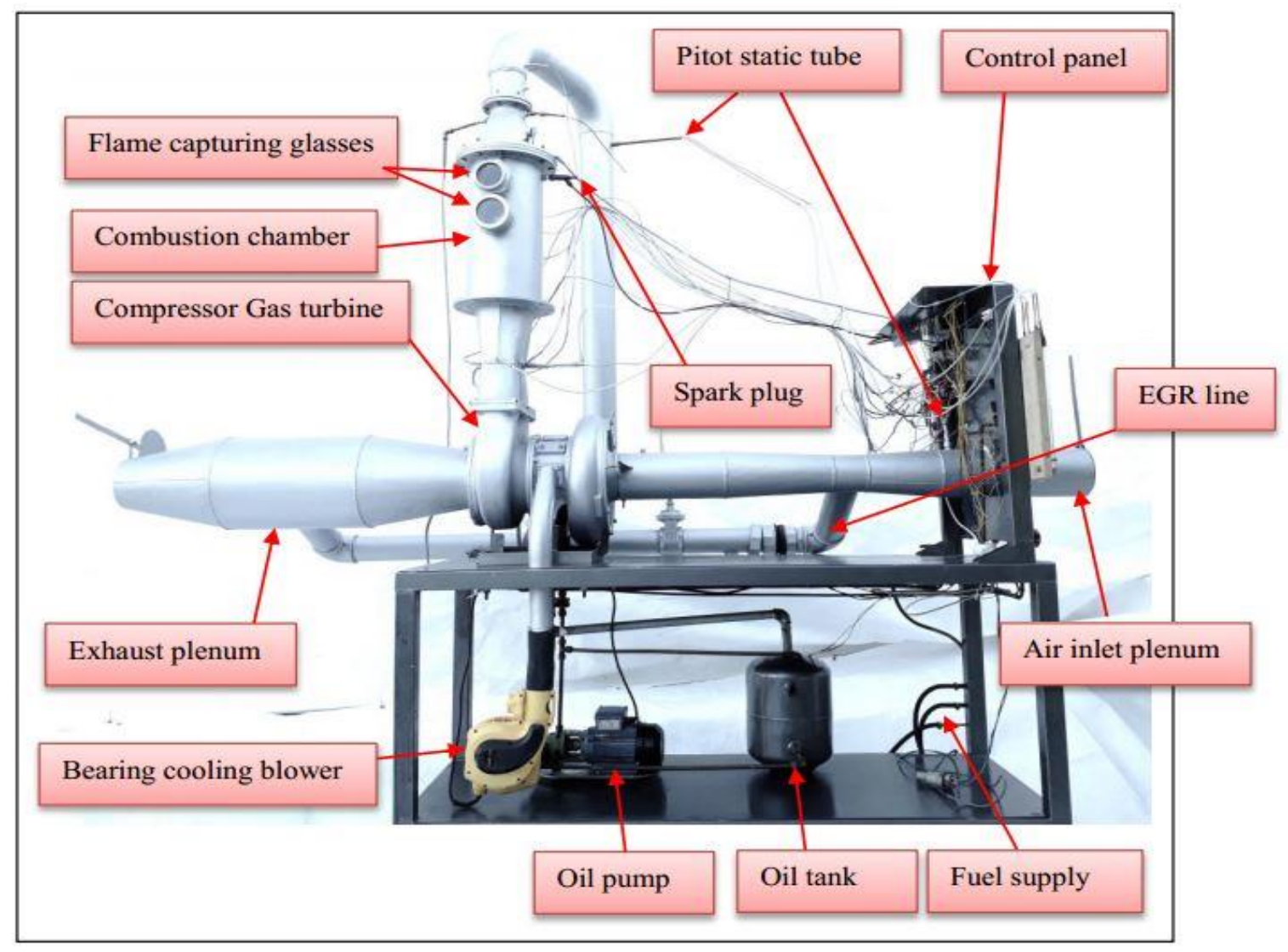

Figure 2. Details of engine parts.

\section{Conventional main injector optimization:}

Related with the experimental steady-state test method and verification of the combustion with conventional main injector case for different injection holes size $(0.5,0.8,1,1.5$ and $2 \mathrm{~mm})$ with swirler of 6 vanes, 60 degrees with the axial direction for each vane, [8] as shown in Figure: 3. In order to measure the centerline temperature along the combustor, outlet temperature profile, emissions gases and capturing flame by camera and combustion efficiency calculation. Both tests were achieved for the same primary, secondary and dilution holes geometry of inline arrangements, number of holes, and size, constant fuel pressure about 2 bar and the range of injected fuel approximately about 0-3.2 g/s of LPG gases fuel. 


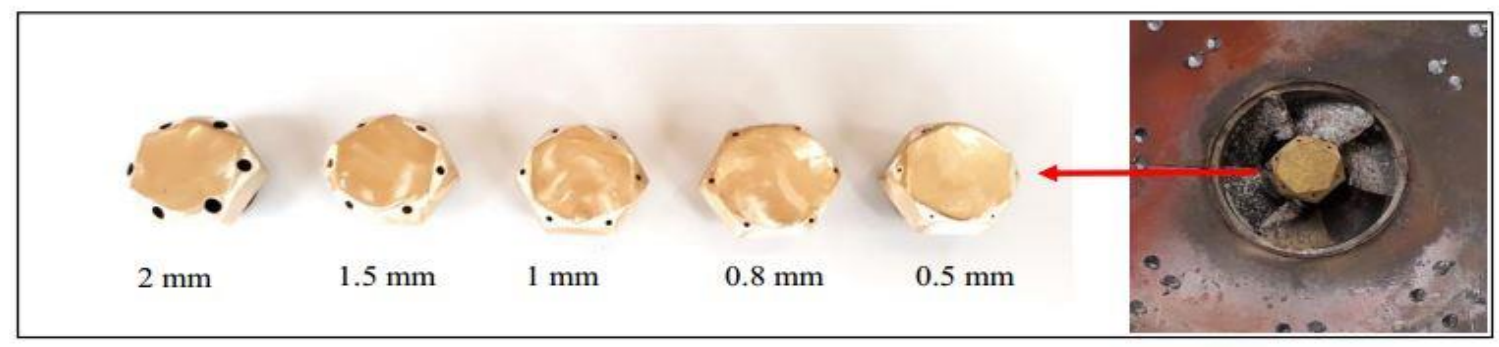

Figure: 3. Swirler with the variable Main injector holes size.

\section{Combustion efficiency calculation:}

The combustion efficiency determined through a measurement of UHC and CO for LPG gas fuel, the imperial relationship of the combustion efficiency, UHC and CO, emissions W. S. Y. Hung [8] is as follows:

$$
\eta_{\mathrm{c}}=1-\left(\mathrm{UHC}_{\mathrm{EI}}+0.211 \mathrm{CO}_{\mathrm{EI}}\right) 10^{-3}
$$

Where $\eta_{c}=$ combustion efficiency

$\mathrm{UHC}_{\mathrm{EI}}=$ emissions index of $\mathrm{UHC}, \mathrm{g} / \mathrm{kg}$ fuel

$\mathrm{CO}_{\mathrm{EI}}=$ emission index of $\mathrm{CO}, \mathrm{g} / \mathrm{kg}$ fuel

The relation between emission index and emission expressed for UHC and $\mathrm{CO}$ at ISO condition are follow as:

$\mathrm{UHC}_{\mathrm{EI}}=0.0288 \mathrm{UHC}$

$\mathrm{CO}_{\mathrm{EI}}=0.0503 \mathrm{CO}$

Where $\mathrm{UHC}=$ emission of $\mathrm{UHC}$ in ppmv.

$\mathrm{CO}=$ emission of $\mathrm{CO}$ in ppmv.

\section{Pattern factor calculation:}

temperature profile at the exit section of the combustor defined as pattern factor represented the temperature homogeneity at the combustor outlet, $\mathrm{H}$. Lefebver [9] as follows:

$$
\text { Pattern factor }=\frac{T_{\max }-T_{4}}{T_{4}-T_{3}} .
$$

\section{Results:}

For 6 holes and $2 \mathrm{~mm}$ injection hole diameter and for $3.2 \mathrm{~g} / \mathrm{s}$ of fuel flow rate results shows very long complete yellow flame approximately up to the total volume of combustor as shown in Figure: 4, a, b due to the low velocity of the fuel flow with respect to the air velocity which directed by the swirlar and high equivalence ratio approximately rich flammability limit with bad mixing rate the turbine running limited with high addle speed approximately 8500 RPM due to effect of yellow flame at the low fuel mass flow rate low speed of fuel flow which caused imperfect mixing (incomplete combustion, low range of enthalpy released) for this case . Low range of UHC about $60 \mathrm{ppmv}, \mathrm{O} 2=0.16 \%$ and high range of $\mathrm{CO}=0.0532 \%$ and high rang of soot generation inside the combustion chamber as shown in Figure: 5. Desirable pattern factor and high average outlet temperature about $883 \mathrm{k}$ due to the distributed long yellow flame which provide temperature homogeneity. Ultimate minimum power generation about $0.53 \mathrm{kw}$, High S.F.C about 21.5 
$\mathrm{kg} / \mathrm{kwh}$ low combustion efficiency due to the generated soot, difficult in starting only by assisting of a secondary line of fuel injection.

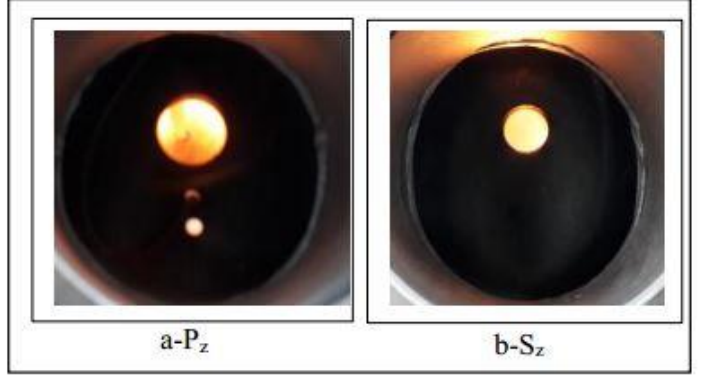

Figure 4 a, b Photographs of flame in primary zone and secondary zone respectively for $2 \mathrm{~mm}$ holes diameter.

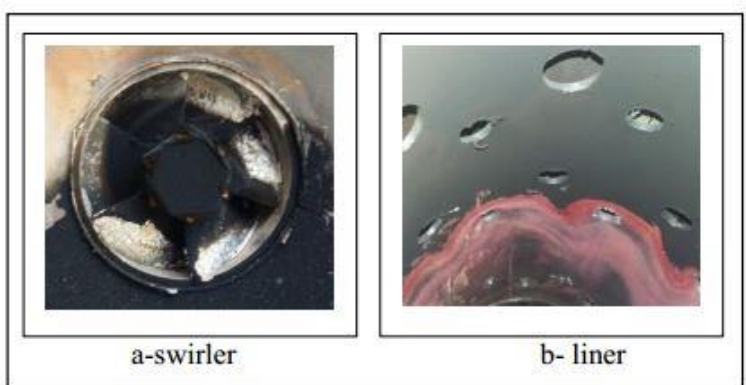

Figure: 5, generated soot inside the combustion chamber.

For 6 holes and $1.5 \mathrm{~mm}$ injection hole diameter with opened dome holes and for $3.2 \mathrm{~g} / \mathrm{s}$ of fuel flow rate results shows long yellow with blue base flame limited approximately up to the total length of secondary zone as presented in Figure: 6, due to the low velocity of the fuel flow with respect to the air velocity which directed by the swirlar which provide bad mixing and with high addle speed approximately 7500 RPM due to effect of yellow flame at the low fuel mass flow rate low speed of fuel flow which caused imperfect mixing (incomplete combustion) for this case and ultimate maximum speed about 10000 RPM due to effects of yellow flame (incomplete fuel heating release, soot generation effects). desirable pattern factor $<0.2$ and high average outlet temperature about $854 \mathrm{k}$ due to the distributed long yellow flame long flame which provides temperature homogeneity Low power generation about $0.82 \mathrm{kw}$, High S.F.C about $14.1 \mathrm{~kg} / \mathrm{kwh}$, difficult to start and low responsive to acceleration. Figure: 7, shows the temperature distribution profile along the center line of combustor the outcome reveals that there is slow decreasing in temperature along the combustor up to the dilution holes due to the effects of slow speed of the turbine which caused decreasing in primary and secondary holes effectiveness and then there is sharp decreasing in temperature, due to effectiveness of the dilution holes.

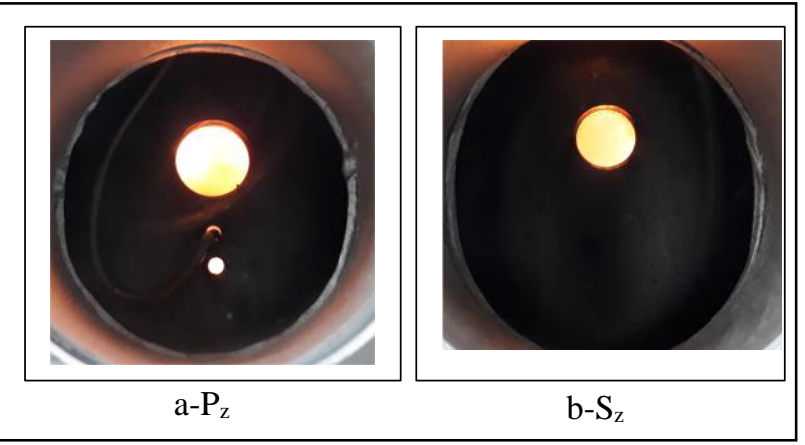

Figure 6 a, $b$ Photographs of flame in primary zone and secondary zone respectively for $1.5 \mathrm{~mm}$ holes

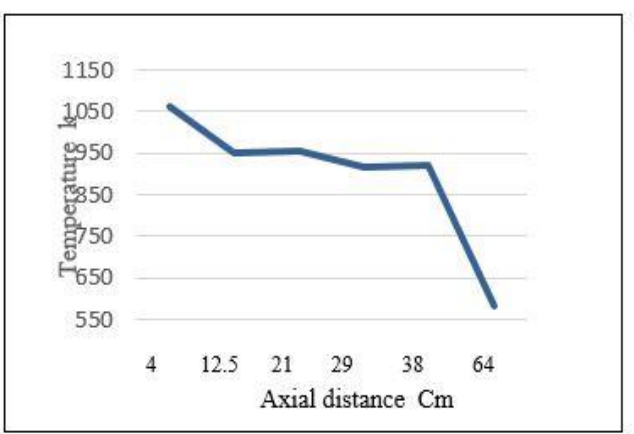

Figure: 7, temperature distribution profile along the center line of the combustion chamber. 
For 6 holes and $1 \mathrm{~mm}$ injection hole diameter and for $3.2 \mathrm{~g} / \mathrm{s}$ of max fuel flow rate results shows intermediate length blue flame limited approximately up to the total distance of secondary zone as shown in Figure: 8, due to the high velocity of the fuel flow with respect to the air velocity which directed by the swirlar which provide good mixing and with intermediate addle speed approximately 6500 RPM due to appearing of yellow flame at the low fuel mass flow rate low speed of fuel flow which caused (imperfect mixing, incomplete combustion) for the addle speed of this case and ultimate maximum speed about 13600 RPM. For no loaded turbine max speed running turbine and Figure: 9, shows the variation of temperature distribution profile along the combustor for different fuel mass flow rate, the outcome reveals that there is sharp decreasing in temperature along the center line of the combustor due to focusing of flame in primary zone and the main role of the primary holes cooling effect on the generated heat also the effect of free loaded turbine caused increasing in turbine speed, decreasing in equivalence ratio with respect to the injected fuel as shown in figure: 10, for combustor performance Figure: 11, shows the variation of pattern factor and average outlet temperature with equivalence ratio for no load max speed running the outcome reveals Desirable and decreasing in pattern factor due to the flame shortening which provide enough time and distance for temperature homogeneity and increase in average outlet temperature due to increases of released heat with respect to the air flow rate. Figure: 12, shows the variation of combustion efficiency with equivalence ratio the results shows increasing in combustion efficiency due to decreasing in emission gases $\mathrm{CO}$ and UHC as shown in figure: 13, High power generation about $3.43 \mathrm{~kW}$, low S.F.C about $3.49 \mathrm{~kg} / \mathrm{kWh}$, easy to start high responsive to acceleration without S.F.I assisting.

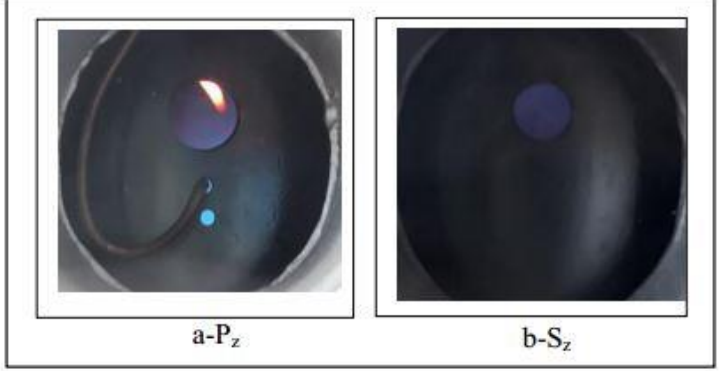

Figure: 8, Photographs of flame in primary zone and secondary zone respectively for $1 \mathrm{~mm}$ holes diameter.

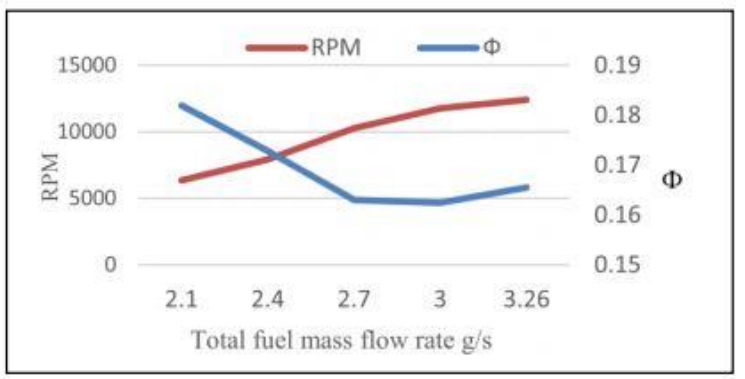

Figure: 10-engine speed and equivalence ratio for no load max speed running.

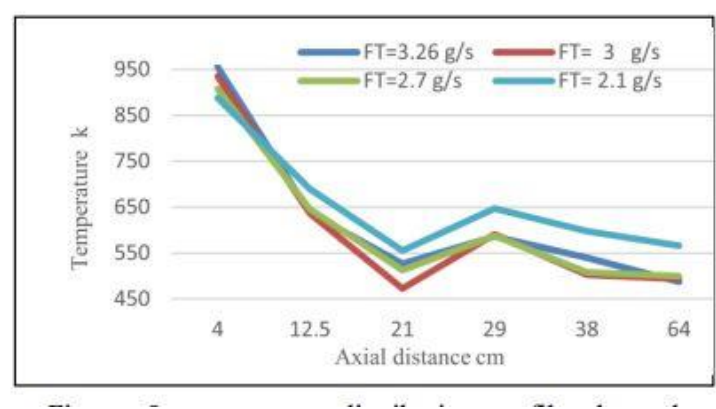

Figure: 9, temperature distribution profile along the center line of the combustion chamber.

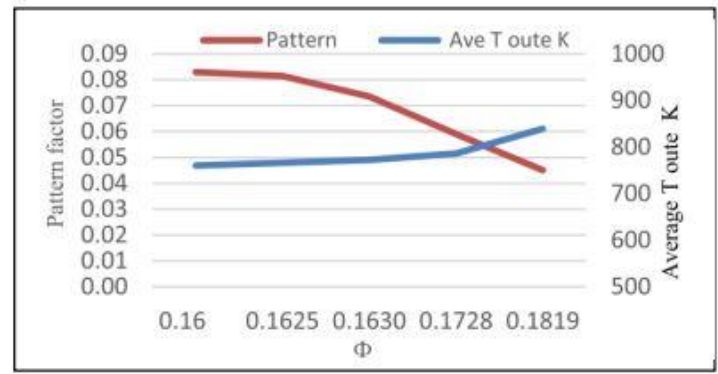

Figure: 11, Pattern factor and average outlet temperature for no load max speed running. 


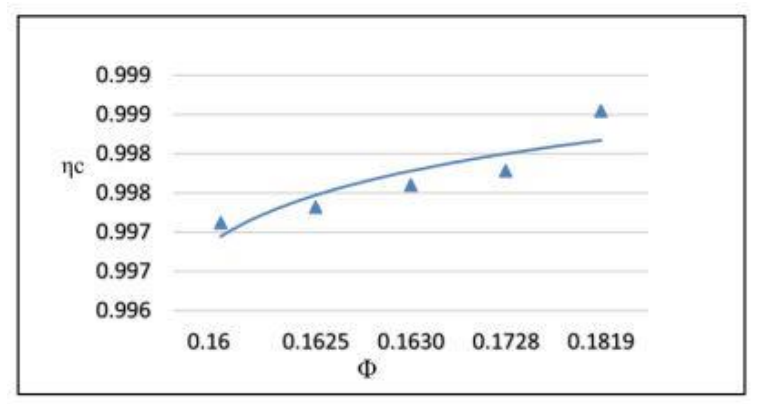

\section{Figure: 12, Combustion efficiency with equivalence ratio.}

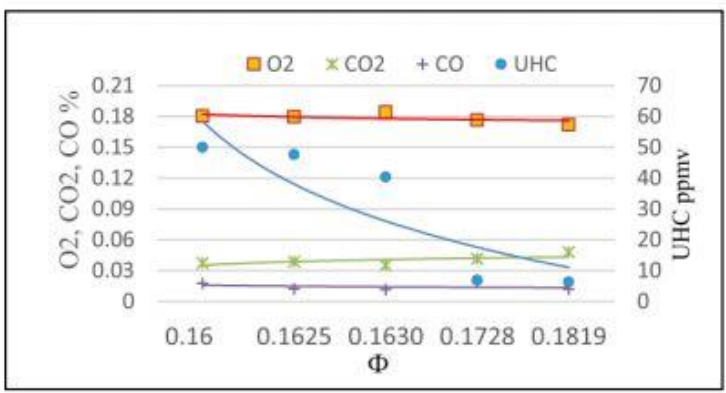

Figure: 13, Emission gases with equivalence ration for no load max speed running.

For 6 holes and $0.8 \mathrm{~mm}$ injection hole diameter and $2.1 \mathrm{~g} / \mathrm{s}$ of max fuel flow rate results shows short blue flame limited approximately to the end of the primary zone as shown in Figure: 14, due to the choked flow of the fuel with respect to the air velocity which directed by the swirlar which provide perfect mixing and dark blue flame in secondary zone as shown in figure: 14 , b, with low addle speed approximately 5500 RPM due to completely absence of the yellow flame (complete combustion) and ultimate maximum speed about 6800 RPM because of the limitation in fuel injection flow rate due to the chocking in fuel flow stream. Desirable pattern factor $<0.2$ due to the flame shortening which provide sufficient time and distance for temperature homogeneity and high outlet temperature about $900 \mathrm{k}$ due low running speed which effect on dilution holes effectiveness. Low power generation about $0.8 \mathrm{~kW}$, high S.F.C about $13.35 \mathrm{~kg} / \mathrm{kwh}$ low combustion efficiency about 0.992 , difficult to start and low responsive to acceleration because of fuel choking in main injector while starting by assisting of S.F.I line.

For 6 holes and $0.5 \mathrm{~mm}$ injection hole diameter (main injector) and $1.2 \mathrm{~g} / \mathrm{s}$ of max fuel flow rate results shows very short blue flame limited approximately to the third quarter of the primary zone as shown in Figure: 15, due to the chocked flow of fuel with respect to the air velocity which directed by the swirlar which provide perfect lean mixture, very dark secondary zone as shown in figure: 15 , b, with constant speed approximately 4500 RPM due to completely absence of the yellow flame, desirable pattern factor $<0.2$ due to the flame shortening which provide sufficient time and distance for temperature homogeneity and high outlet temperature about $920 \mathrm{k}$ due low running speed which effect on dilution holes effectiveness . Low power generation about $0.32 \mathrm{~kW}$, high S.F.C about $17 \mathrm{~kg} / \mathrm{kWh}$, difficult to start.

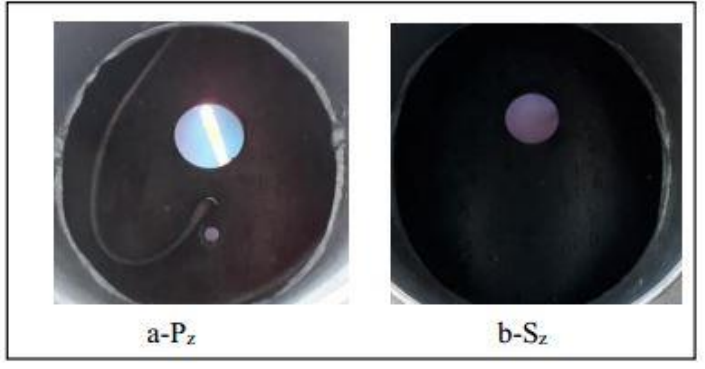

Figure: 14, Photographs of flame in primary zone and secondary zone respectively for 0.8 mm diameter.

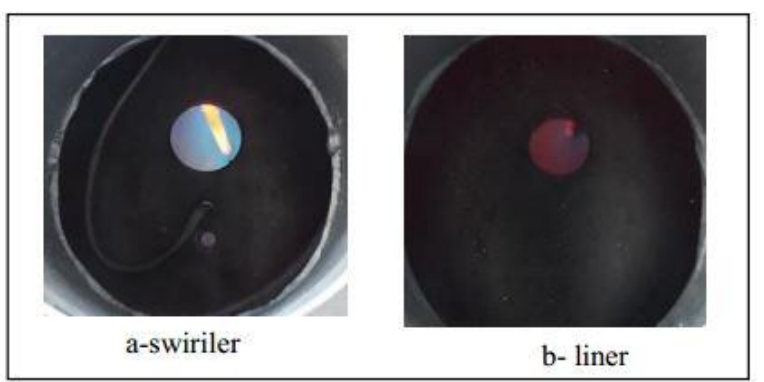

Figure: 15, Photographs of flame in primary zone and secondary zone respectively for $0.5 \mathrm{~mm}$ diameter.

Main injector optimization for colorless combustion consideration (high efficient combustion) for $3.2 \mathrm{~g} / \mathrm{s}$ of fuel flow rate results shows that the main injectors holes diameter $1 \mathrm{~mm}$ is more efficient for this consideration where figure: 16 shows the effects of the fuel choking with main injector of 0.5 and $0.8 \mathrm{~mm}$ caused low running speed low air flow rate and reduction in primary and secondary holes effectiveness which caused increasing in outlet temperature while the same behavior with main injector of 1.5 and $2 \mathrm{~mm}$ and the effects of a long flame with soot generation for 1.5 and $2 \mathrm{~mm}$ of holes diameter which caused soot generation and high equivalence ratio caused low running speed and increasing in outlet temperature and pattern factor, 
while for engine performance figure: 17, shows the same behavior where there is decreasing in specific fuel consumption and increasing in power generation up to $1 \mathrm{~mm}$ injection holes diameter because of vanishes of choking effects and then decreasing in power generation and increasing in specific fuel consumption due to increasing in soot generation and appearing of yellow flame which represents incomplete combustion.

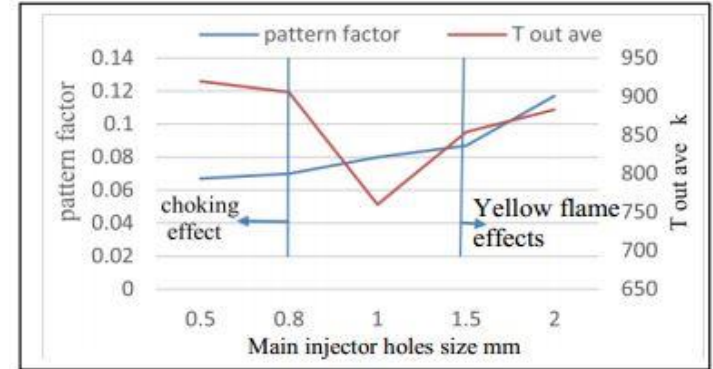

Figure: 16, variation of pattern factor and average outlet temperature with the main injector holes size.

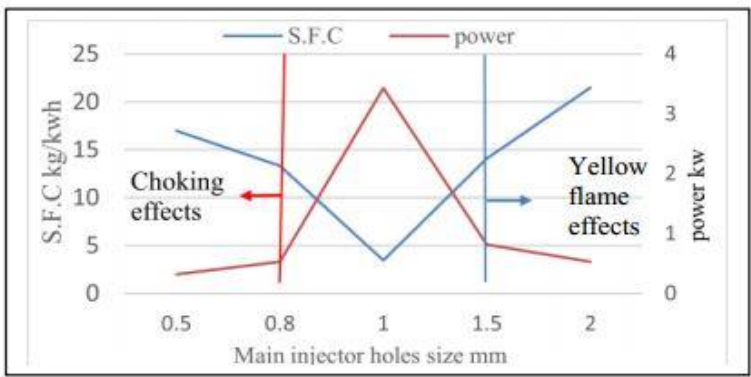

Figure: 17, variation of S.F.C and outlet power with the main injector holes size.

\section{Conclusions:}

In this paper a colorless flame high-performance combustion (volumetric oxidation reaction) by experimental investigation using optimization of volumetric reaction phenomenon by using multi-size of fuel injection holes diameter to burned gaseous fuel (LPG). It is found that to achieve colorless flame combustion is heavily dependent on combustor design, the method of fuel injection. Following are the conclusions of this study based on the objectives.

1. The colorless flame combustion mode occurred only for a limited range of conditions at fuel lean conditions and high airflow rates.

2. The colorless flame combustor achieved extremely low NO, CO and UHC when the distributed flame was formed (distribution of hotspot).

3. High fuel mass flow rates (choking range) with respect to air mass flow rate helped in promoting good mixing and strong reaction resulting in a high temperature field, thus higher UHC and CO level when compared with lower flow rate at the same equivalence ratio. However, at the same flame temperature, high airflow rate formed less $\mathrm{UHC}$ and $\mathrm{CO}$ because of the more evenly distributed flame.

4. Large combustor exhaust contraction accelerated the local flow and reduced the residence time necessary for complete burning of UHC and CO oxidation.

5. The present design optimization for multi-size of the main fuel injection colorless combustor can achieve low UHC, NOx and CO emissions with low-pressure loss.

\section{CONFLICT OF INTERESTS.}

- There are no conflicts of interest.

\section{References:}

[1] S. h.Cohen, G.F.C. Rogers, Gas Turbine Theory, Fourth ed. Longman Group Limited, Essex, England, Book, 1996.

[2] J. W. Sawyer, "Gas Turbine Engineering Handbook, Theory and Design," Turbomach. Int. Publ. USA, pp. 5-1 to 5-62., vol. 1, p. 350, 1985.

[3] J. A. W. and J. G. Wiinning, "FLAMELESS OXIDATION TO REDUCE THERMAL NOFORMATION,” Prog. Energy ComlnaL Sci., vol. 23, pp. 81-94, 1997.

[4] C. Ghenai, "Combustion of Syngas Fuel in Gas Turbine Can Combustor Combustion of Syngas Fuel in 
Gas Turbine Can Combustor," Adv. Mech. Eng. · January 2010 DOI 10.1155/2010/342357 - Source DOAJ, no. May, p. 13, 2015.

[5] F. Pathan, N. Patel, and M. Tadvi, "Numerical Investigation of the Combustion of Methane Air Mixture in Gas Turbine Can-Type Combustion Chamber," Ijser.Org, vol. 3, no. 10, pp. 1-7, 2012.

[6] P. S. Kumar and P. P. Rao, "Design and Analysis of Gas Turbine Combustion Chamber," Int. J. Comput. Eng. Res. Vol. 03 Issue. 12, vol. 3, pp. 36-40, 2013.

[7] E. Oliveira, J. R. Barbosa, and W. P. Martignoni, "Influence of Air Intake Holes's Position for Primary and Secondary Zones on the Pattern Factor for Gas Turbine with Annular Combustors Designed for Ethanol," in International Conference Data Mining, Civil and Mechanical Engineering (ICDMCME'2014), Feb 4-5, 2014 Bali (Indonesia), 2014.

[8] W. S. Y. Hung, "Carbon Monoxide Emissions From Gas Turbines as Influenced by Ambient Temperature and Turbine Load," J. Eng. Gas Turbines Power, vol. 115, no. 3, pp. 1-10, 1993.

[9] H. Lefebvre and D. R. Ballal, Gas Turbine Combustion alternative fuel and Emissions, THIRD EDIT. Printed in the United States of America on acid-free paper $10987654321,1999$. 


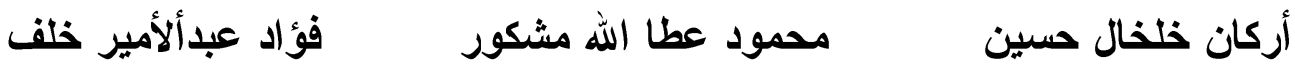 قسم الهندسه الميكانيكبه، الجامعه التكنلو جبه، بغداد، العراق}

me.21325@uotechnology.edu.iq MahmoodMashkoor@hotmail.com arkanltaie@yahoo.com

\section{الخلاصة}

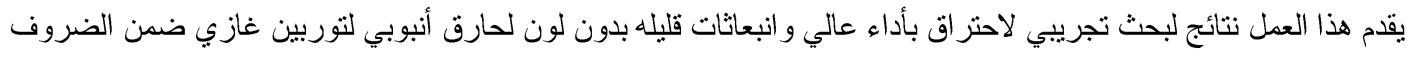

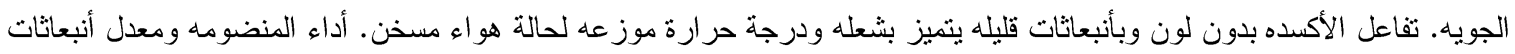

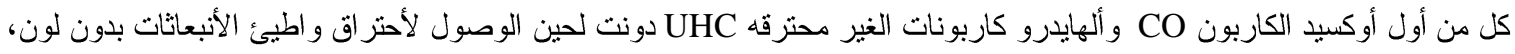

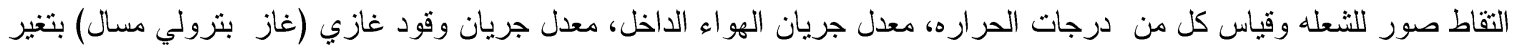

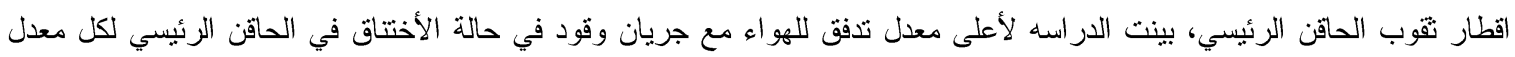

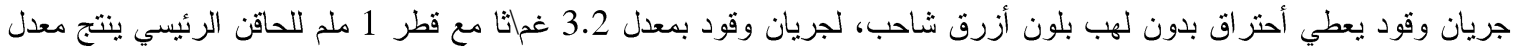

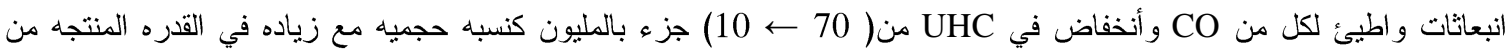

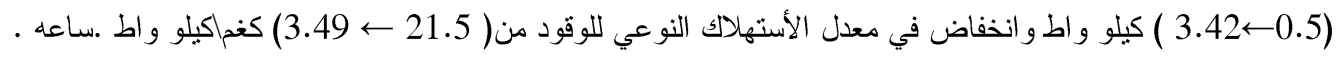
الكلمات الدالة: توربين غازي، حراق انبوبي، أحتراق بدون لهب، انبعاث و اطيئ، وقود غاز بترولي مسال. 